\title{
Correlation of Bone Mineral Parameters with Anthropometric Measurements and the Effect of Glucocorticoids on Bone Mineral Parameters in Congenital Adrenal Hyperplasia: Correspondence
}

\author{
Aashima Dabas ${ }^{1}$ \\ Received: 27 February 2016 / Accepted: 9 May 2016 / Published online: 24 May 2016 \\ (C) Dr. K C Chaudhuri Foundation 2016
}

To the Editor: With reference to the recently published article on assessment of bone mineral density (BMD) in congenital adrenal hyperplasia [1], here are few remarks which need mention. Height has a significant influence on bone mass/density [2]. The relevance of including Figures 1 and 2 needs to be explained. Instead, the impact of age or fat mass on BMD in this cohort could have been analyzed. The authors have commented on significant decrease in the bone mass with increasing duration of steroid use in Table 3 . The values depicted in the table show higher values in the group which received longer duration of steroids. As per assumption, was this because the mean age of children in the latter group was older which resulted in higher BMD in those receiving longer duration of steroids than younger subjects? The authors can clarify the same and provide details of analysis which support their conclusion. Alternately, a difference between the BMD of study subjects and BMD of comparative age/gender matched controls for younger ages or published Indian references for children $\geq 5$ y [3] could have been used for comparison. Lastly, the authors may consider interpretation of bone mineral apparent density (BMAD) than BMD for the analysis to compensate for bone size [4].
Compliance with Ethical Standards

Conflict of Interest None.

Source of Funding None.

\section{References}

1. Ganesh R, Suresh N, Janakiraman L, Ravikumar K. Correlation of bone mineral parameters with anthropometric measurements and the effect of glucocorticoids on bone mineral parameters in congenital adrenal hyperplasia. Indian J Pediatr. 2016;83:126-30.

2. Rio L, Carrascosa A, Pons F, Gusinye M, Yeste D, Domenech FM. Bone mineral density of the lumbar spine in white mediterranean Spanish children and adolescents: changes related to age, sex, and puberty. Pediatr Res. 1994;35:362-6.

3. Khadilkar AV, Sanwalka NJ, Chiplonkar SA, Khadilkar VV, Mughal MZ. Normative data and percentile curves for dual energy X-ray absorptiometry in healthy Indian girls and boys aged 5-17 years. Bone. 2011;48:810-9.

4. Carter D, Bouxsein M, Marcus R. New approaches for interpreting projected bone densitometry data. J Bone Miner Res. 1992;7: $137-45$.
Aashima Dabas

dr.aashimagupta@gmail.com

1 Department of Pediatrics, Chacha Nehru Bal Chikitsalaya, New Delhi 110031, India 